Article

\title{
Analysis of Guided Wave Propagation in a Multi-Layered Structure in View of Structural Health Monitoring †
}

\author{
Yevgeniya Lugovtsova ${ }^{1, *}$, Jannis Bulling ${ }^{1}$, Christian Boller ${ }^{2}$ and Jens Prager ${ }^{1}$ \\ 1 Bundesanstalt für Materialforschung und -prüfung (BAM), 12205 Berlin, Germany; \\ jannis.bulling@bam.de (J.B.); jens.prager@bam.de (J.P.) \\ 2 Chair of NDT and Quality Assurance (LZfPQ), Saarland University, 66125 Saarbruecken, Germany; \\ c.boller@mx.uni-saarland.de \\ * Correspondence: yevgeniya.lugovtsova@bam.de \\ + This paper is an extended version of our paper published in 9th European Workshop on Structural Health \\ Monitoring (EWSHM 2018), 10-13 July 2018 in Manchester, UK.
}

Received: 25 September 2019; Accepted: 25 October 2019; Published: 29 October 2019

check for updates

\begin{abstract}
Guided waves (GW) are of great interest for non-destructive testing (NDT) and structural health monitoring (SHM) of engineering structures such as for oil and gas pipelines, rails, aircraft components, adhesive bonds and possibly much more. Development of a technique based on GWs requires careful understanding obtained through modelling and analysis of wave propagation and mode-damage interaction due to the dispersion and multimodal character of GWs. The Scaled Boundary Finite Element Method (SBFEM) is a suitable numerical approach for this purpose allowing calculation of dispersion curves, mode shapes and GW propagation analysis. In this article, the SBFEM is used to analyse wave propagation in a plate consisting of an isotropic aluminium layer bonded as a hybrid to an anisotropic carbon fibre reinforced plastics layer. This hybrid composite corresponds to one of those considered in a Type III composite pressure vessel used for storing gases, e.g., hydrogen in automotive and aerospace applications. The results show that most of the wave energy can be concentrated in a certain layer depending on the mode used, and by that damage present in this layer can be detected. The results obtained help to understand the wave propagation in multi-layered structures and are important for further development of NDT and SHM for engineering structures consisting of multiple layers.
\end{abstract}

Keywords: lamb waves; composite; ultrasonic testing; numerical modelling; pressure vessels

\section{Introduction}

Guided waves (GW) are of great interest for non-destructive testing (NDT) and structural health monitoring (SHM) of engineering structures such as for oil and gas pipelines, rails, aircraft components, adhesive bonds and possibly much more [1-5]. These waves can propagate over relatively long distances as long as the structure's cross-section stays constant and the difference of acoustic impedance to the surrounding environment is large. It may further allow investigation of inaccessible areas of the structure under given circumstances. To minimise complexity in GW based analysis mainly the fundamental (i.e., first symmetric and antisymmetric) modes are used in the lower frequency range, since those are well understood and can be excited, measured and consequently analysed without difficulty [6,7]. Techniques based on GWs are therefore still under investigation to explore the more complex applications such as wave propagation in hybrid structures. For instance, some structures are composed of a fibre-reinforced composite and a metal of constant cross-section [8-13]. This is a popular design of composite pressure vessels (COPV) used for gas storage. To date, a standard 
test procedure for this type of vessels does not exist and needs to be developed. Various approaches have been proposed to assess the current degradation state of COPVs. Destructive tests of some of the vessels running in parallel with vessels being in service were suggested in [14]. Another approach is acoustic emission monitoring for prediction of the residual lifetime of COPVs [11,15]. Many researchers have been exploring an option of monitoring pressure vessels using integrated optical fibres with Bragg grating sensors [16-20]. Another promising approach is guided wave-based monitoring $[10,12,13,21-23]$, which has several advantages when compared to alternative monitoring techniques. One of the advantages is that the approach is non-destructive and another is the approach's holistic character with respect to detection and localisation of damage.

To examine different features of guided waves with respect to the limits of detectability of damage in a structure to be monitored, specifically also with regard to location when considering the hybrid material mentioned above, higher-order modes provide an interesting option to be explored. These modes, when considered over the whole thickness of the laminate, do not necessarily have smaller wavelengths but rather possess more complex mode shapes. This, in turn, may allow damage located in different depths to be found and differentiated. Due to dispersion and the multimodal character of GWs, development of a damage detection technique based on GWs requires careful numerical modelling such that a realistic analysis of wave propagation and mode-damage interaction can be performed.

At first, a tool for calculation of dispersion curves and mode shapes is required. For this purpose, efficient approaches have been developed and applied to layered structures, e.g., the transfer matrix method [24], the discrete layer method [25], the semi-analytical finite element method [26,27] and the scaled boundary finite element method (SBFEM) [28]. Based on these curves, appropriate modes can be identified and considered for further analysis. Next, a numerical tool for modelling the propagation of the chosen GW modes is required. Numerous methods have been applied to wave propagation problems such as finite differences [29], finite volumes [30-32], and finite element methods [11,33], to just name a few. An extensive review of simulation methods for guided wave propagation analysis can be found in [34]. In general, each method has its advantages and disadvantages depending on the given problem, and there is no universal method suitable for solving every problem efficiently.

In this article, the SBFEM is used to analyse GW propagation in a plate consisting of an isotropic aluminium layer bonded to an anisotropic laminate made of carbon fibre reinforced plastics (CFRP). Compared to other methods, the SBFEM does not require full discretisation, thus reducing the computational effort required significantly. It is suitable for calculation of dispersion curves, mode shapes and modelling of the GW propagation $[28,35,36]$. The dispersion curves are computed with the SBFEM by discretising the cross-section (e.g., the plate thickness) of an infinite domain using high-order elements, as shown as an example in Figure 1a. Multi-layered structures can be easily modelled using one element per layer having either isotropic or anisotropic material properties. This method is also highly efficient for modelling of the wave propagation in structures which have a constant cross-section. Because only the cross-section is discretised, the number of finite elements used in the SBFEM reduces drastically when compared to common finite element methods, as can be seen as a comparison between the SBFEM discretisation in Figure $1 \mathrm{~b}$ and the FEM discretisation in Figure 1c, respectively. Another feature of the SBFEM is that an infinite domain, a so-called unbounded domain, as shown in Figure 1a, can be coupled with the domain of interest, thus avoiding unwanted reflections and by that simplifying the analysis of the wave propagation.

To be able to distinguish a damage in the aluminium from a damage in the CFRP in the hybrid composite addressed above, fundamental and higher-order GW modes have been determined and analysed. Additionally, to some research performed and reported in [13], a delamination case has been studied and is reported here proposing a new damage detection methodology, which allows damage localisation within the different layers. The results show that most of the wave energy (displacement) concentrates in a certain layer of the hybrid composite depending on the mode being considered and with this a damage present in the respective layer may be detected. The results obtained help 
to understand the wave propagation in such a multi-layered structure which may further help GW based techniques to be enhanced in the sense of NDT and SHM systems to be developed for hybrid composite structures.

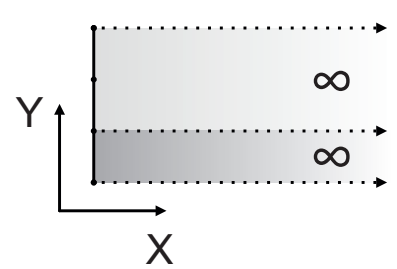

(a)

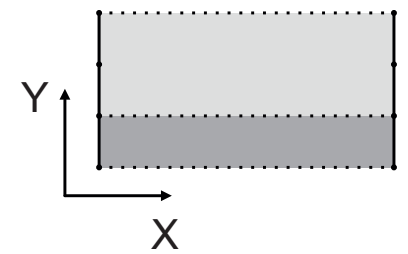

(b)

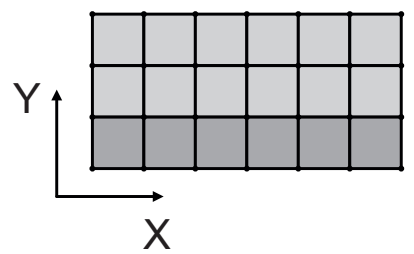

(c)

Figure 1. Schematic discretisation of: (a) an unbounded (infinite) domain in the scaled boundaty finite element method (SBFEM) (b); a domain in the SBFEM; and (c) in classical FEM.

\section{Methodology}

Tubular composite pressure vessels are designed in a way that failure mainly happens in their cylindrical part. There, axial (longitudinal) cracks in the metal liner, as well as fibre fracture and epoxy matrix cracks in the CFRP overwrap, can occur $[14,37,38]$. These types of damage, together with an impact damage $[39,40]$, which may happen too, are the most critical and crucial issues with regard to a safe use of the COPV. In the work presented here and for reasons of simplification, the end caps of the vessel are neglected, and wave propagation is modelled in the circumferential (hoop) direction only. This will not only allow to detect axial cracks but also to concentrate on the circumferential CFRP plies, which are holding most of the pressure in the vessel. Furthermore, it allows damage detectability in such a hybrid material to be studied still under less complex loading conditions before moving to the more complex ones. In terms of the GW propagation, the cylindrical structure is therefore approximated to a plate, being allowed if the ratio of radius to thickness is larger than 10:1 [41]. The scope of this paper is merely to investigate the GW propagation in a multi-layered plate first while cylindrical structures need to be discussed in some future paper later. Figure 2 shows the configuration used.

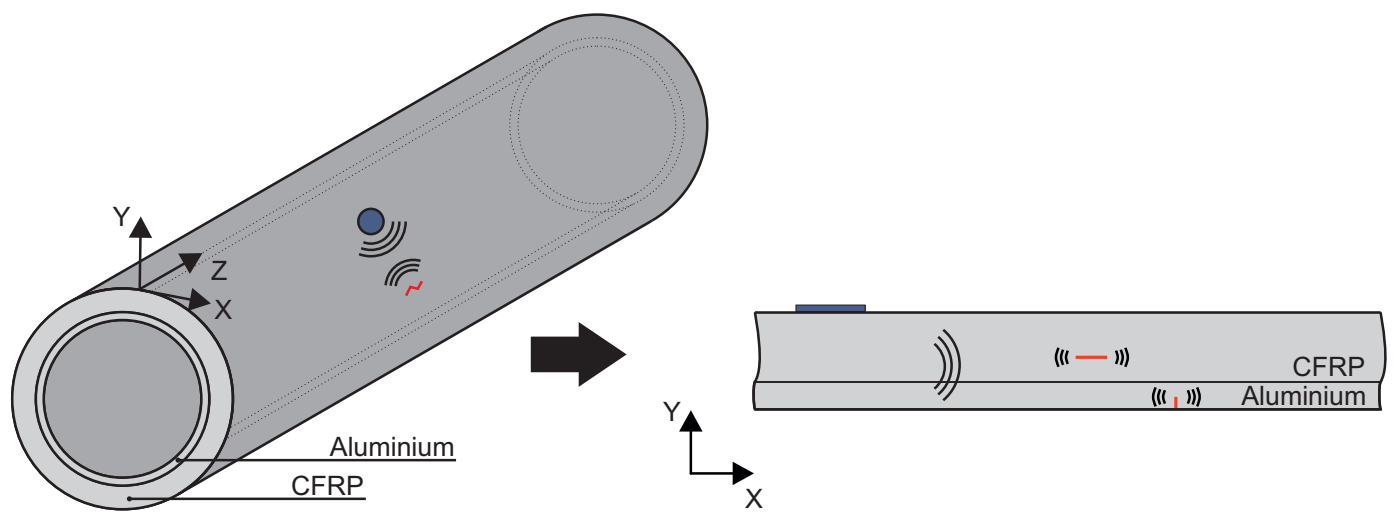

Figure 2. Sketch of a simplified structure of a COPV with corresponding sensor placement, adapted from [13].

The numerical model considered consists of a plate made of a $4 \mathrm{~mm}$ CFRP laminate with a [90/0/90/0] layup (from top to bottom), followed by a $2 \mathrm{~mm}$ aluminium layer. Modelling was performed under the two-dimensional plain strain assumption. The CFRP plies were modelled separately as a stack in accordance to their lamination direction being transversally isotropic with a $1 \mathrm{~mm}$ thickness of each. Material properties from the ANSYS database were used in the model and are listed in Tables 1 and 2, where $\rho$ is density, $E$ is Young's modulus, $G$ is shear modulus, and $v$ is Poisson's ratio. Due to the production process of COPVs, a firm connection between the aluminium liner and CFRP overwrap is achieved, which allows a firm bonding between the two parts of the structure 
to be considered. To calculate the dispersion curves and mode shapes, the plate thickness has been approximated using finite elements of the eighth order, whereas the domain in the wave propagation direction is described analytically, as shown in Figure 1a. For the analysis of wave propagation, an excitation domain, an evaluation domain, a damage domain and two unbounded domains at both ends of the plate were used. The schematic of the numerical model is shown in Figure 3.

Table 1. Material properties of the epoxy carbon ply used ( $E_{1}$ is in the fibre direction).

\begin{tabular}{cccccc}
\hline$\rho\left(\mathrm{kg} / \mathrm{m}^{\mathbf{3}}\right)$ & $E_{\mathbf{1}}(\mathrm{GPa})$ & $E_{2}, E_{\mathbf{3}}(\mathrm{GPa})$ & $G_{\mathbf{1 2}}, G_{\mathbf{1 3}}(\mathrm{GPa})$ & $v_{\mathbf{1 2}}, v_{\mathbf{1 3}}$ & $v_{\mathbf{2}}$ \\
\hline 1490 & 121 & 8.6 & 4.7 & 0.27 & 0.4 \\
\hline
\end{tabular}

Table 2. Material properties of aluminium used.

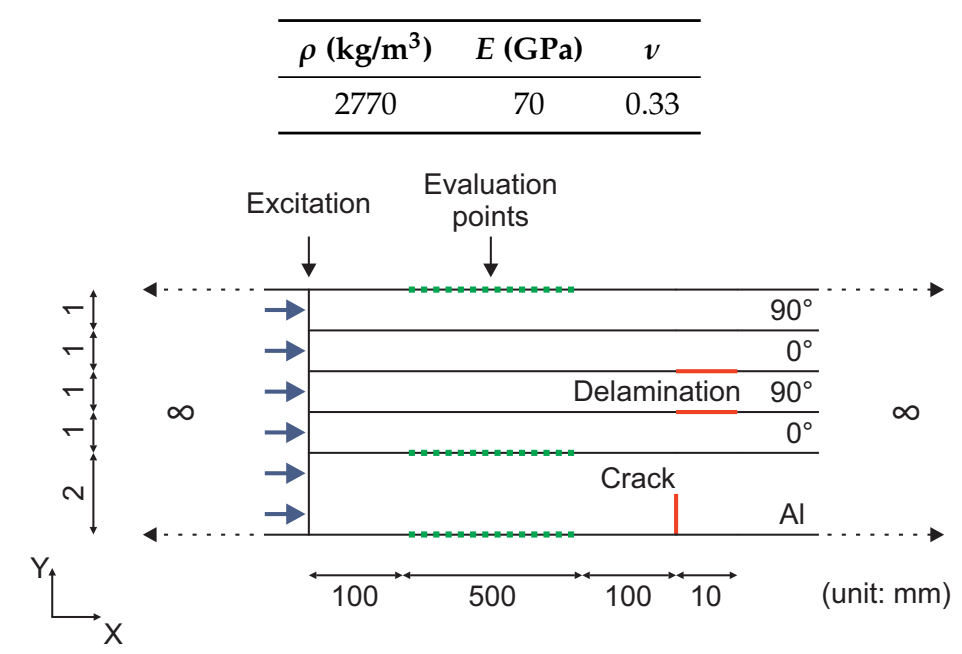

Figure 3. Schematic of the numerical model used in the SBFEM.

When actuating/deflecting the laminate at virtually any location over its cross-section, different mode shapes will be generated in accordance to the frequency being applied. To minimise the effect of dispersion by minimising a change in group velocities, some centre operation frequencies can be chosen, which have been marked with circles in Figure 4. For those, the mode shapes have been determined for which examples are shown in Figure 6. These mode shapes have further been used as the excitation to simulate a respective mode within the laminate and to understand the resulting consequences. The excitation was performed in both horizontal and vertical directions where the load distribution over the plate has been in accordance to the shape of the mode having been considered. These were pre-calculated using the unbounded domain in the SBFEM, for which an example is shown in Figure 1a. Even though such an excitation can be hardly realised in real application it has been used here for reasons of simplification and validation only and mainly to study the behaviour of a single respective mode. The excitation in time was a Hanning-windowed tone burst with the centre frequency of the desired mode. Data were evaluated using 4096 points over a $500 \mathrm{~mm}$ distance resulting in a $0.12 \mathrm{~mm}$ step. Modelling was performed in the frequency domain allowing the use of infinite domains.

For GW to be accepted for COPVs' health monitoring, damage must be detected in any part of the structure, be it the aluminium liner or the CFRP overwrap. To allow for damage detection in both parts, modes showing characteristic interaction with damage, therefore, need to be identified. For this, damage in the aluminium part was modelled by disconnecting two SBFEM domains, representing a crack of $1 \mathrm{~mm}$ in depth and zero width, respectively. Damage in the CFRP part was modelled by disconnecting two SBFEM boundaries, representing a delamination of $10 \mathrm{~mm}$ in length and zero width between two CFRP-plies. The delamination was modelled at two different positions in two separate simulation runs. The positions were between the second ply and the third ply (Position (1)), and the third ply and the fourth ply (Position (2)) (counted from top to bottom). Figure 3 schematically shows 
the different locations of the damages. It further shows that the excitation has been chosen to act along the thickness while the recordings have been made on the top and bottom of the hybrid composite as well as between the CFRP and aluminium part respectively being denoted as "evaluation points".

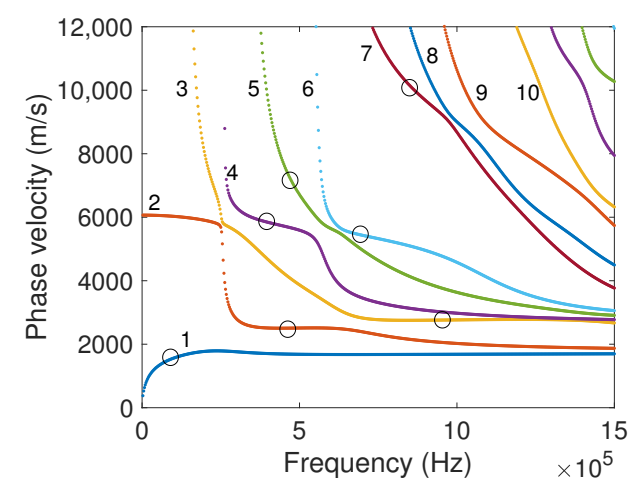

(a)

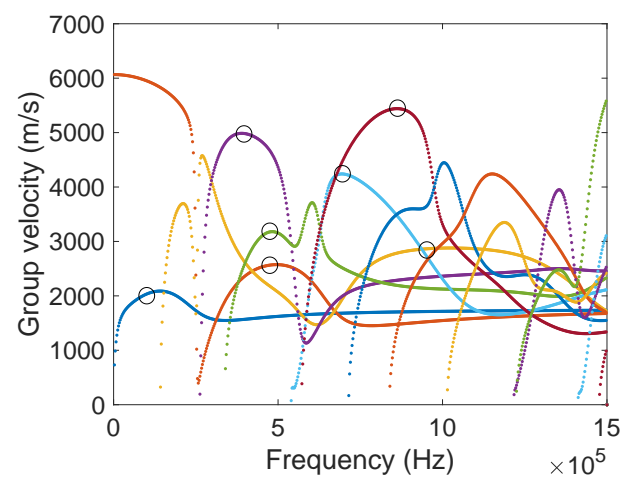

(b)

Figure 4. Dispersion curves of: (a) phase and (b) group velocities, calculated for the infinite aluminium-CFRP hybrid plate using SBFEM. The first ten guided wave modes are numbered in numerical order. The circles mark modes, as chosen for numerical modelling. Recreated from original data from [13].

\section{Results}

Dispersion curves for the infinite aluminium-CFRP hybrid plate are presented in Figure 4. The circles mark modes at their centre operation frequencies, as chosen for the numerical modelling. These points were selected based on the minimal change of the group velocity, which in turn allows dispersion effects of the mode to be minimised. All values from dispersion curves and the number of cycles in the tone burst used for modelling are summarised in Table 3. The number of cycles was chosen based on the frequency. The higher the frequency was, the more cycles were used in the pulse. This allows the frequency bandwidth to be kept narrow, which also minimises the dispersion effects, allows the excitation of undesired modes to be avoided beyond their cut-off frequencies and reduces the computational time. The longest computational times on the standard desktop PC used for the determination of the dispersion curves and wave propagation were $5 \mathrm{~s}$ and $278 \mathrm{~s}$, respectively.

Table 3. Modes used for numerical modelling.

\begin{tabular}{cccccc}
\hline Mode & $\begin{array}{c}\text { Frequency } \\
\mathbf{k H z}\end{array}$ & $\begin{array}{c}\text { Group Velocity } \\
\mathbf{m} / \mathbf{s}\end{array}$ & $\begin{array}{c}\text { Phase Velocity } \\
\mathbf{m} / \mathbf{s}\end{array}$ & $\begin{array}{c}\text { Wavelength } \\
\mathbf{m m}\end{array}$ & \begin{tabular}{c} 
Number of Cycles \\
\hline 1
\end{tabular} \\
\hline 100 & 2033 & 1562 & 15.6 & 10 \\
2 & 475 & 2565 & 2507 & 5.3 & 20 \\
3 & 950 & 2864 & 2761 & 2.9 & 30 \\
4 & 400 & 4981 & 5839 & 14.6 & 20 \\
5 & 475 & 3175 & 7132 & 15 & 20 \\
6 & 700 & 4238 & 5431 & 7.8 & 20 \\
7 & 860 & 5440 & 10,005 & 11.6 & 30 \\
\hline
\end{tabular}

\subsection{Damage in the Aluminium Liner}

The signals obtained from the evaluation points, shown in Figure 3, were analysed by means of a 2D Fast Fourier Transform (FFT). The resulting dispersion map is in the frequency-wavenumber domain. It reveals different modes propagating in the plate and reflecting from the crack in the aluminium liner. The frequency-wavenumber spectra were superimposed with the dispersion curves to identify different modes, and the results are shown in Figure 5. The negative wavenumbers represent incident waves, whereas positive wavenumbers represent reflected waves. Two cases are compared in this figure, for the excitation of Mode 2 at $475 \mathrm{kHz}$ (see Figure 5a,b) and of Mode 5 at $475 \mathrm{kHz}$ 
(see Figure $5 c, d$ ), where in the cases in-plane and out-of-plane components have been determined, respectively. These examples are shown for the evaluation points positioned at the interface between aluminium and CFRP. Even though the excitation was performed by applying the corresponding mode shape at the central frequency of the desired mode to be excited, the excitation of other modes could not be avoided. However, these modes have much smaller displacements when compared to the mode having been explicitly excited. In the case of Mode 2 excitation, Mode 4 was excited too, whereas excitation of Mode 5 led to the excitation of Modes 1,2 and 4, as shown in Figure 5. Because of the same excitation frequency and the number of cycles in the pulse, but different mode shapes, different modes were excited. The results show that, regardless of how many modes were excited in the plate, only Modes 2 and 4 reflect from the crack in the frequency range used.

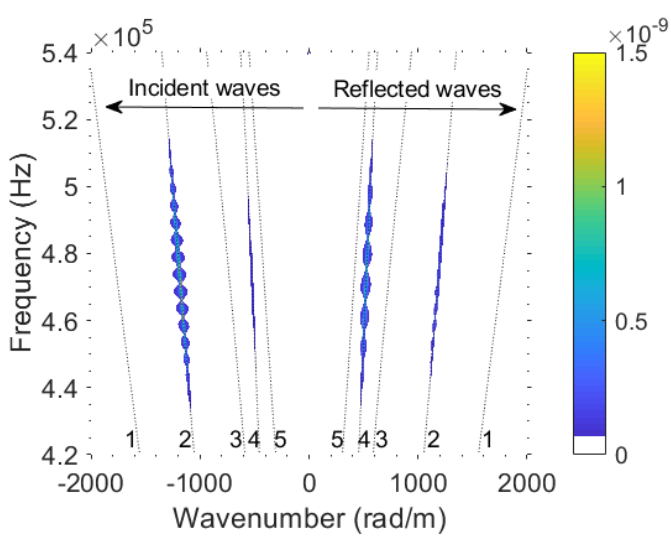

(a)

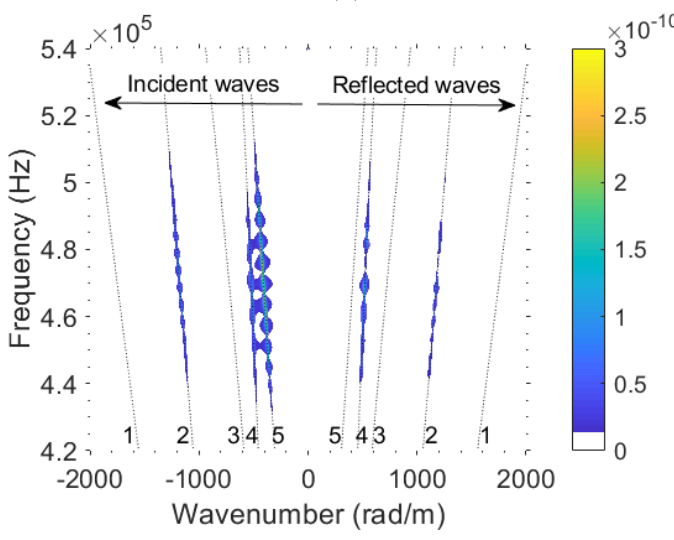

(c)

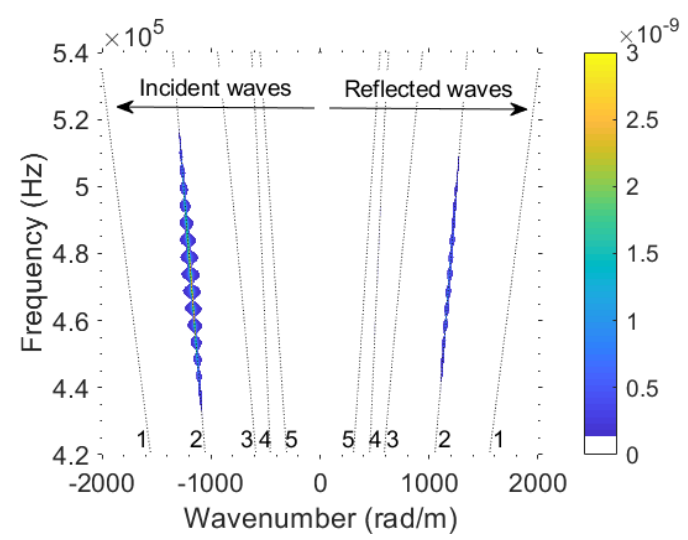

(b)

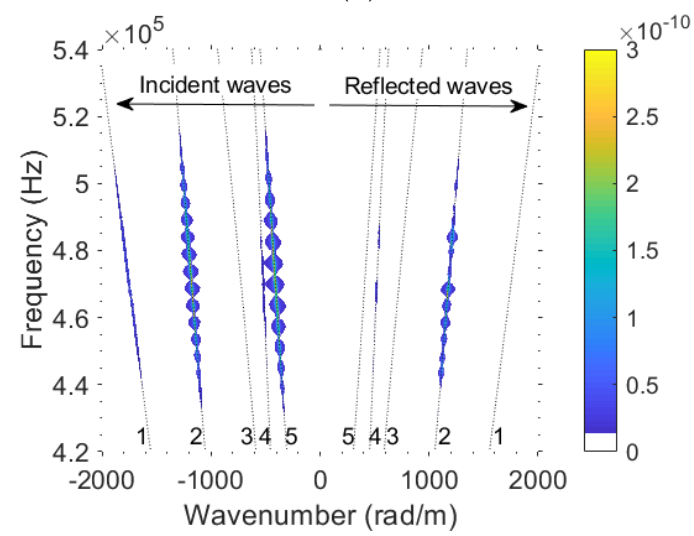

(d)

Figure 5. Frequency-wavenumber spectra of wave modes propagating in the aluminium-CFRP plate and reflecting from the $1 \mathrm{~mm}$ crack in the aluminium: (a) for in-plane and (b) out-of-plane components while exciting Mode 2 at $475 \mathrm{kHz}$, and (c) for in-plane and (d) out-of-plane components while exciting Mode 5 at $475 \mathrm{kHz}$.

Considering the shapes of Modes 2 and 5, shown in Figure 6a,b, respectively, it is observed that Mode 5 has a very small displacement in the aluminium at this frequency, compared to the CFRP part and Mode 2. This indicates that the energy (displacement) of Mode 5 at the frequency of $475 \mathrm{kHz}$ is concentrated mainly in the CFRP layers, and thus the damage in the aluminium layer cannot be found. The frequencies for all modes chosen for modelling, including the detectability of all damages defined, are summarised in Table 4. As regards the crack in the aluminium liner only Modes 5 and 7 do not interact. Considering the mode shapes, Mode 5 has a very small displacement in the aluminium layer compared to the CFRP plies (see Figure 6b). The same holds for Mode 7, not shown here for brevity. In contrast, other modes that were investigated have comparable amplitudes in both aluminium and CFRP parts (see Figure $6 \mathrm{a}, \mathrm{c}, \mathrm{d}$ ). In Figure $7 \mathrm{a}, \mathrm{b}$, the dispersion curves of the coupled 
$6 \mathrm{~mm}$ aluminium-CFRP plate are compared to the dispersion curves of a single $2 \mathrm{~mm}$ aluminium plate and a single $4 \mathrm{~mm}$ CFRP plate, respectively. The dashed lines represent four guided wave modes in the $2 \mathrm{~mm}$ aluminium plate for the frequency range chosen. The modes propagating in the $4 \mathrm{~mm}$ CFRP plate are marked with dashed-dotted lines in Figure $7 \mathrm{~b}$. The combination of these two structural parts being the hybrid composite considered results in the set of guided wave modes shown with solid lines. Filled and hollow circles mark modes that did and did not interact with a $1 \mathrm{~mm}$ crack in the aluminium layer, respectively. It is observed in Figure $7 \mathrm{a}$ that the modes of the hybrid composite are positioned near the modes of the pure aluminium portion (marked with red dashed lines) and showed characteristic interaction with the crack (see filled circles). Modes marked with hollow circles lay on the modes of the pure CFRP portion and did not reflect from the crack (see red dashed-dotted lines in Figure $7 \mathrm{~b}$ ). These modes have very small displacements in the aluminium, as shown in Figure $6 \mathrm{~b}$ as an example. Thus, modes of the hybrid composite show different behaviour, with either the CFRP or the aluminium portion dominating, or both. Such an effect is very much known from the behaviour of coupled vibrations in multi-body systems. The displacement is concentrated either in the CFRP plies or in the aluminium layer, or within both parts depending on the mode and frequency chosen. Such behaviour, when carefully analysed and understood, can be advantageous, allowing for damage detection in different constituent parts of a component.

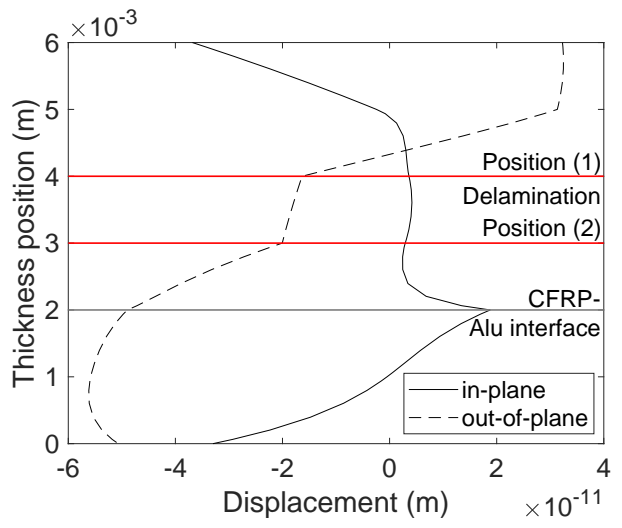

(a)

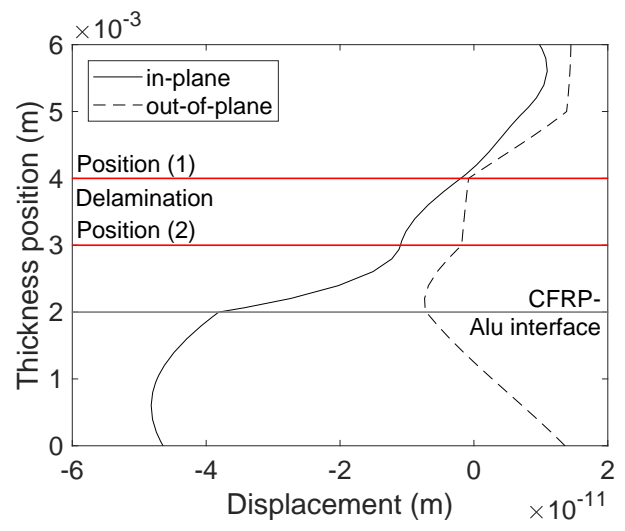

(c)

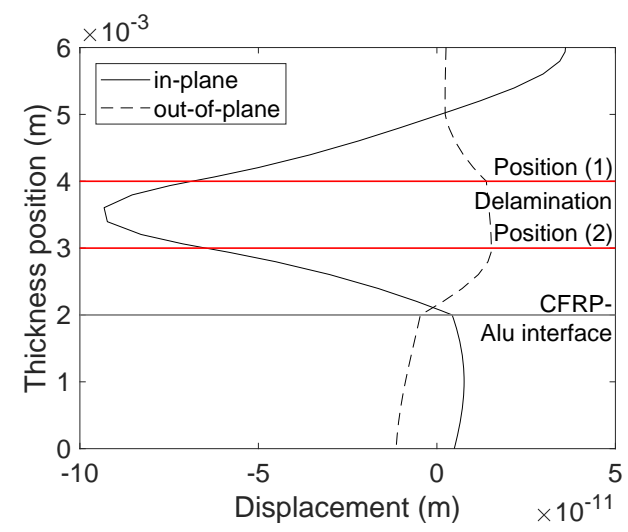

(b)

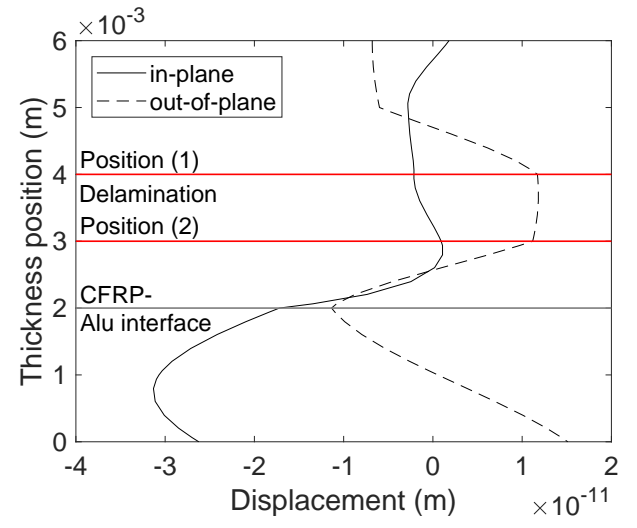

(d)

Figure 6. Mode shapes of: (a) Mode 2 at $475 \mathrm{kHz}$; (b) Mode 5 at $475 \mathrm{kHz}$; (c) Mode 4 at $400 \mathrm{kHz}$; and (d) Mode 6 at $700 \mathrm{kHz}$. Red lines mark delamination placed between the second and the third ply (Position (1)), and the third and the fourth ply (Position (2)) (counted from top to bottom). 


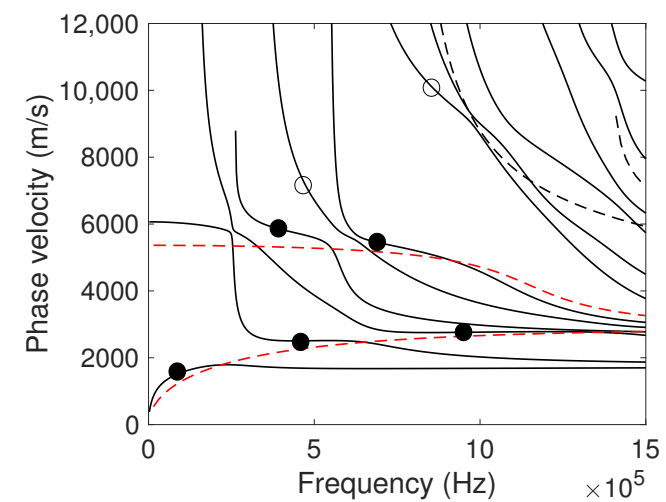

(a)

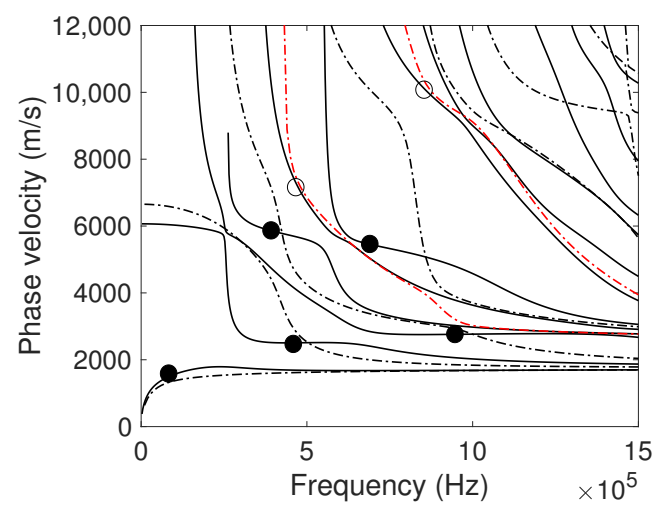

(b)

Figure 7. Combined phase velocity dispersion curves of: (a) the $2 \mathrm{~mm}$ aluminium plate (dashed lines) and the $6 \mathrm{~mm}$ aluminium-CFRP plate (solid lines); and (b) the $4 \mathrm{~mm}$ CFRP plate with a [90/0/90/90] layup (dash-dotted lines) and the $6 \mathrm{~mm}$ aluminium-CFRP plate (solid lines). The filled and hollow circles mark modes that did and did not interact with a $1 \mathrm{~mm}$ crack in aluminium, respectively. Red dashed lines mark two aluminium modes in the aluminium, red dash-dotted lines mark two CFRP modes. Recreated from original data from [13].

\subsection{Damage in the CFRP Overwrap}

Damage in the CFRP was modelled as a delamination having a $10 \mathrm{~mm}$ length and zero width. The delamination was placed at two positions between different CFRP plies, as shown in Figure 3 . Position (1) corresponds to the delamination placed between the second and the third ply, whereas Position (2) corresponds to the delamination between the third and the fourth ply (counted from top to bottom). Modelling was performed in two separate simulation runs, and the same modes, shown in Table 3, were used. Figure 8 shows the resulting frequency-wavenumber spectra of the propagating modes and modes reflected from the delamination at Position (2). Excitation was performed for Modes 2 and 5 at $475 \mathrm{kHz}$, and signals were evaluated at points positioned at the interface between aluminium and CFRP. In contrast to the crack in the aluminium, from which only Modes 2 and 4 reflect, more modes interact with the delamination in the CFRP. These are Modes 1, 2, 3 and 5, whereas Mode 4 did not interact with the delamination at Position (2). The results for all modes being modelled are summarised in Table 4. Modes 4, 6 and 7 did not interact with the delamination at Position (2), whereas only Mode 6 did not interact with the delamination at Position (1). As in the case of the crack in the aluminium, this can be attributed to the mode shape. Every mode modelled has comparable or bigger displacement amplitudes between the aluminium and CFRP parts (see the example shown for some modes in Figure 6). For instance, Modes 2 and 5 reflect from the delamination even though the in-plane displacement of Mode 2 is almost zero at both delamination positions (see Figure 6a), whereas, for Mode 5, it is the out-of-plane displacement which is close to zero (see Figure 6b). Mode 4 interacts with the delamination placed at Position (1), but not at Position (2). The out-of-plane displacement is almost equal at these positions, and the in-plane displacement is even bigger in the latter case. A contribution to this behaviour may further be the anisotropic properties of the CFRP and its layup. Numerical modelling was also performed under 2D conditions and it could be that the guided wave modes reflect, and scatter but, in another direction, which has not been modelled so far. In general, it is difficult to draw fundamental conclusions at this stage as long as such multi-layered systems are not systematically researched and described answering the question why some modes do interact with the delamination, whereas the others do not. However, the importance of numerical modelling of guided wave propagation and analysis, including their interaction with damage, is again highly emphasised with the test case presented here. 


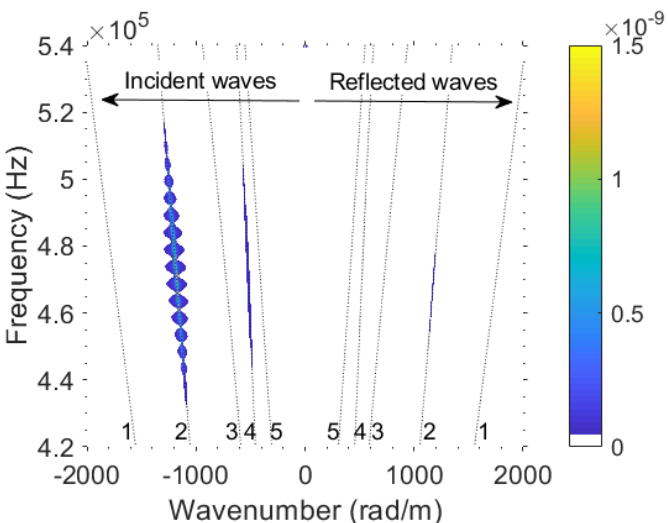

(a)

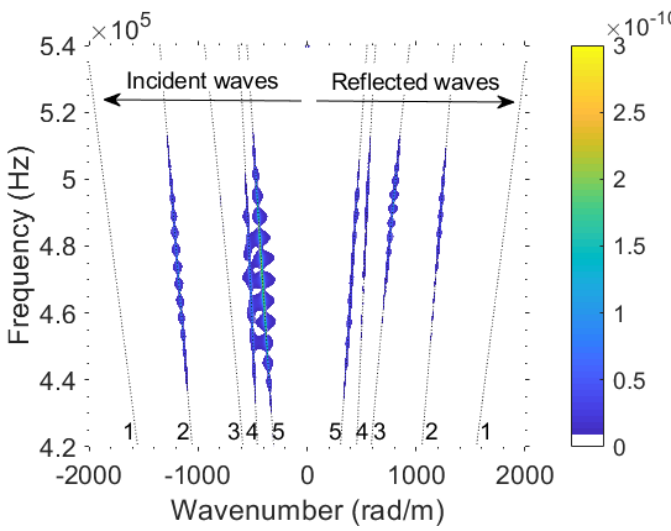

(c)

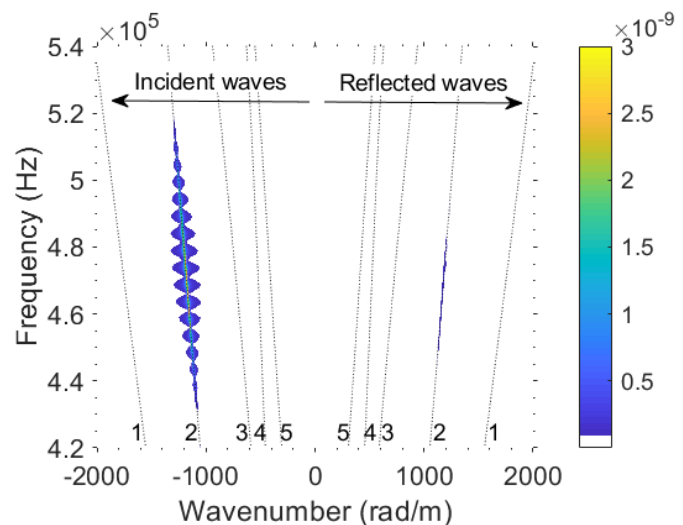

(b)

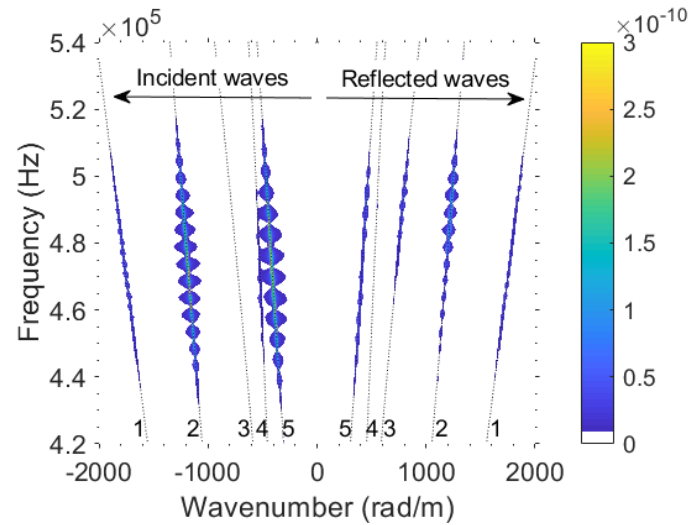

(d)

Figure 8. Frequency-wavenumber spectra of wave modes propagating in the aluminium-CFRP plate and reflecting from the $10 \mathrm{~mm}$ delamination between the third and the fourth ply [Position (2)]: (a) for in-plane and (b) out-of-plane components while exciting Mode 2 at $475 \mathrm{kHz}$, and (c) for in-plane and (d) out-of-plane components while exciting Mode 5 at $475 \mathrm{kHz}$.

Table 4. Comparison of the mode-damage interaction for the damage positioned in different parts of the structure. $\checkmark$, modes which reflect from the damage; $\boldsymbol{X}$, modes which did not reflect from the damage.

\begin{tabular}{cccccc}
\hline Mode & $\begin{array}{c}\text { Frequency } \\
\text { kHz }\end{array}$ & $\begin{array}{c}\text { Wavelength } \\
\text { mm }\end{array}$ & $\begin{array}{c}\text { Crack in } \\
\text { Aluminium }\end{array}$ & $\begin{array}{c}\text { Delamination } \\
\text { at Position (1) }\end{array}$ & $\begin{array}{c}\text { Delamination } \\
\text { at Position (2) }\end{array}$ \\
\hline 1 & 100 & 15.6 & $\checkmark$ & $\checkmark$ & $\checkmark$ \\
2 & 475 & 5.3 & $\checkmark$ & $\checkmark$ & $\checkmark$ \\
3 & 950 & 2.9 & $\checkmark$ & $\checkmark$ & $\checkmark$ \\
4 & 400 & 14.6 & $\checkmark$ & $\checkmark$ & $\boldsymbol{X}$ \\
5 & 475 & 15 & $\boldsymbol{x}$ & $\checkmark$ & $\boldsymbol{x}$ \\
6 & 700 & 7.8 & $\checkmark$ & $\boldsymbol{x}$ & $\boldsymbol{X}$ \\
7 & 860 & 11.6 & $\boldsymbol{x}$ & $\checkmark$ & \\
\hline
\end{tabular}

\section{Discussion}

The example described above demonstrates that multi-layered structures are rather complex when it comes to the description of guided waves travelling through them. To understand this, numerical analysis tools are of an essential need. In the case considered here, the SBFEM was used to calculate dispersion curves and mode shapes, as well as to analyse the propagation of guided waves in a plate consisting of an isotropic metal bonded to anisotropic carbon fibre reinforced layered material. The method allows appropriate modes to be identified and their interaction with different damage types to be analysed. 
Results show that there are wave modes, which are sensitive to the damage defined in the composite and metallic part of the structure, represented in Modes 1-3 with respect to the case described here. To be therefore able to separate the damage in the aluminium liner from the damage in the CFRP overwrap, the characteristic interaction of a mode sensitive to the damage only in one part is needed. This has been observed for Mode 4 in the case of the crack in the aluminium liner and for Mode 5 in the case of the delamination at both positions defined in CFRP. One has to be careful here, in the sense that the right modes are used and that a damage in the CFRP part will not be mistaken for a damage in the aluminium liner. This is why it is important to be able to excite modes in different constituent parts of the component, and that chosen modes show characteristic interaction only with the damage in one of the parts. As a remark, in the present work, a case of the CFRP being delaminated at numerous locations across the thickness has not been considered so far, which would represent an impact damage. Supposedly, more modes may interact with such an impact damage, and this may result in higher amplitudes of the reflected modes than in the case of a single delamination considered here. As for micro-cracking of the CFRP overwrap, a different approach is necessary where guided wave modes are analysed based on the change of their phase [10] or group velocity [13], and not the reflection from the damage.

A solution in that regard for the reception as well as the excitation of the desired modes could be an interdigital transducer (IDT) being specifically "tuned" to the frequency and wavelength sensitive to the respective damage to be monitored. A $15 \mathrm{~mm}$ pitch between its electrodes may be suitable for the cases described here, which corresponds to Modes 4 and 5 when driven at $400 \mathrm{kHz}$ and $475 \mathrm{kHz}$, respectively. Excitation of Mode 4 will allow the damage in the aluminium part and excitation of Mode 5 the damage in the CFRP part to be identified. A design of such an IDT based monitoring system could be to get it integrated at the aluminium-CFRP interface. The monitoring system configuration (pattern) should be adapted to as many modes as possible being sensitive to the damage to be monitored. Here, thin and flexible polymer materials such as PVDF can be used. Their thickness may be less than $100 \mu \mathrm{m}$, they can be poled to achieve piezo-electric properties, and their electrodes can be structured in the desired manner to excite the wave mode needed [42-47]. A sketch of a proposed arrangement with regard to structural integration is shown in Figure 9.

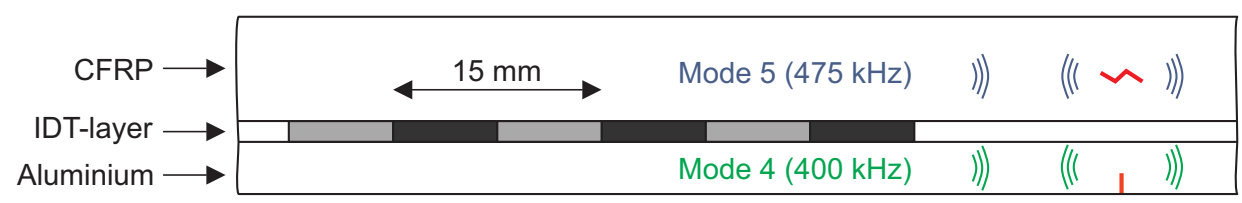

Figure 9. Sketch of an arrangement based on the example considered here for an interdigital SHM system for a composite pressure vessel monitoring.

\section{Conclusions}

In this contribution, the scaled boundary finite element method was used to calculate dispersion curves and mode shapes, as well as to analyse the propagation of guided waves in a plate consisting of an isotropic metal bonded to anisotropic carbon fibre reinforced layered material. The method allows appropriate modes to be identified and their interaction with different damage types to be analysed. The results show that most of the wave energy can be concentrated in a certain layer depending on the mode used, and by that damage present in this respective layer can be detected. The results obtained help to understand the wave propagation in such a multi-layered structure, which may further help guided wave based techniques to be enhanced in the sense of non-destructive testing and structural health monitoring systems to be developed for hybrid composite structures. Moreover, a concept for an SHM system for composite pressure vessels is proposed.

Author Contributions: Conceptualisation, Y.L., J.B., C.B. and J.P.; investigation, Y.L.; software, J.B.; data curation, Y.L.; writing—original draft preparation, Y.L.; writing—review and editing, Y.L., J.B., C.B. and J.P.; and supervision, C.B. and J.P. 
Funding: This research received no external funding.

Conflicts of Interest: The authors declare no conflict of interest.

\section{References}

1. Standard Practice for Guided Wave Testing of Above Ground Steel Pipework Using Piezoelectric Effect Transduction; ASTM International: West Conshohocken, PA, USA, 2016.

2. Fromme, P.; Wilcox, P.D.; Lowe, M.J.S.; Cawley, P. On the development and testing of a guided ultrasonic wave array for structural integrity monitoring. IEEE Trans. Ultrason. Ferroelectr. Freq. Control 2006, 53, 777-785. [CrossRef] [PubMed]

3. Wilcox, P.; Evans, M.; Pavlakovic, B.; Alleyne, D.; Vine, K.; Cawley, P.; Lowe, M. Guided wave testing of rail. Insight Non-Destr. Test. Cond. Monit. 2003, 45, 413-420. [CrossRef]

4. Gao, H.; Rose, J.L. Ice detection and classification on an aircraft wing with ultrasonic shear horizontal guided waves. IEEE Trans. Ultrason. Ferroelectr. Freq. Control 2009, 56, 334-344. [CrossRef] [PubMed]

5. Rose, J.; Zhu, W.; Zaidi, M. Ultrasonic NDT of titanium diffusion bonding with guided waves. Mater. Eval. 1998, 56, 535-539.

6. Diamanti, K.; Soutis, C. Structural health monitoring techniques for aircraft composite structures. Prog. Aerosp. Sci. 2010, 46, 342-352. [CrossRef]

7. Mitra, M.; Gopalakrishnan, S. Guided wave based structural health monitoring: A review. Smart Mater. Struct. 2016, 25. [CrossRef]

8. Gao, H. Ultrasonic Guided Wave Mechanics for Composite Material Structural Health Monitoring. Ph.D. Thesis, Pennsylvania State University, State College, PA, USA, 2007.

9. Yu, X.; Fan, Z.; Castaings, M.; Biateau, C. Feature guided wave inspection of bond line defects between a stiffener and a composite plate. NDT E Int. 2017, 89, 44-55. [CrossRef]

10. Castaings, M.; Hosten, B. Ultrasonic guided waves for health monitoring of high-pressure composite tanks. NDT E Int. 2008, 41, 648-655. [CrossRef]

11. Sause, M.G.; Hamstad, M.A.; Horn, S. Finite element modeling of lamb wave propagation in anisotropic hybrid materials. Compos. Part Eng. 2013, 53, 249-257. [CrossRef]

12. Lugovtsova, Y.; Prager, J. Structural health monitoring of composite pressure vessels using guided ultrasonic waves. Insight-Non-Destr. Test. Cond. Monit. 2018, 60, 139-144. [CrossRef]

13. Lugovtsova, Y.; Bulling, J.; Prager, J.; Boller, C. Efficient modelling of guided ultrasonic waves using the Scaled Boundary FEM towards SHM of composite pressure vessels. In Proceedings of the 9th European Workshop on Structural Health Monitoring, Manchester, UK, 10-13 July 2018.

14. Mair, G.W.; Scherer, F.; Duffner, E. Concept of interactive determination of safe service life for composite cylinders by destructive tests parallel to operation. Int. J. Press. Vessel. Pip. 2014, 120-121, 36-46. [CrossRef]

15. Chou, H.; Mouritz, A.; Bannister, M.; Bunsell, A. Acoustic emission analysis of composite pressure vessels under constant and cyclic pressure. Compos. Part Appl. Sci. Manuf. 2015, 70, 111-120. [CrossRef]

16. Degrieck, J.; Waele, W.D.; Verleysen, P. Monitoring of fibre reinforced composites with embedded optical fibre Bragg sensors, with application to filament wound pressure vessels. NDT E Int. 2001, 34, 289-296. [CrossRef]

17. Kang, D.; Kim, C.; Kim, C. The embedment of fiber Bragg grating sensors into filament wound pressure tanks considering multiplexing. NDT E Int. 2006, 39, 109-116. [CrossRef]

18. Gassior, P.; Malesa, M.; Kaleta, J.; Kujawińska, M.; Malowany, K.; Rybczyński, R. Application of complementary optical methods for strain investigation in composite high pressure vessel. Compos. Struct. 2018, 203, 718-724. [CrossRef]

19. Xiao, B.; Yang, B.; Xuan, F.Z.; Wan, Y.; Hu, C.; Jin, P.; Lei, H.; Xiang, Y.; Yang, K. In-Situ Monitoring of a Filament Wound Pressure Vessel by the MWCNT Sensor under Hydraulic Fatigue Cycling and Pressurization. Sensors 2019, 19, 1396. [CrossRef]

20. Saeter, E.; Lasn, K.; Nony, F.; Echtermeyer, A.T. Embedded optical fibres for monitoring pressurization and impact of filament wound cylinders. Compos. Struct. 2019, 210, 608-617. [CrossRef]

21. Bulletti, A.; Giannelli, P.; Calzolai, M.; Capineri, L. An Integrated Acousto/Ultrasonic Structural Health Monitoring System for Composite Pressure Vessels. IEEE Trans. Ultrason. Ferroelectr. Freq. Control 2016, 63, 864-873. [CrossRef] 
22. Yaacoubi, S.; McKeon, P.; Ke, W.; Declercq, N.; Dahmene, F. Towards an Ultrasonic Guided Wave Procedure for Health Monitoring of Composite Vessels: Application to Hydrogen-Powered Aircraft. Materials 2017, 10, 1097. [CrossRef]

23. Yang, B.; Xiang, Y.; Xuan, F.Z.; Hu, C.; Xiao, B.; Zhou, S.; Luo, C. Damage localization in hydrogen storage vessel by guided waves based on a real-time monitoring system. Int. J. Hydrogen Energy 2019. [CrossRef]

24. Lowe, M.J.S. Matrix techniques for modeling ultrasonic waves in multilayered media. IEEE Trans. Ultrason. Ferroelectr. Freq. Control 1995, 42, 525-542. [CrossRef]

25. Kausel, E. Wave propagation in anisotropic layered media. Int. J. Numer. Methods Eng. 1986, 23, 1567-1578. [CrossRef]

26. Dong, S.B.; Nelson, R.B. On Natural Vibrations and Waves in Laminated Orthotropic Plates. J. Appl. Mech. 1972, 39, 739-745. [CrossRef]

27. Dong, S.B.; Huang, K.H. Edge Vibrations in Laminated Composite Plates. J. Appl. Mech. 1985, 52, $433-438$. [CrossRef]

28. Gravenkamp, H.; Song, C.; Prager, J. A numerical approach for the computation of dispersion relations for plate structures using the Scaled Boundary Finite Element Method. J. Sound Vib. 2012, 331, 2543-2557. [CrossRef]

29. Xu, K.; Ta, D.; Su, Z.; Wang, W. Transmission analysis of ultrasonic Lamb mode conversion in a plate with partial-thickness notch. Ultrasonics 2014, 54, 395-401. [CrossRef]

30. Fellinger, P.; Marklein, R.; Langenberg, K.; Klaholz, S. Numerical modeling of elastic wave propagation and scattering with EFIT-Elastodynamic finite integration technique. Wave Motion 1995, 21, 47-66. [CrossRef]

31. Schubert, F.; Peiffer, A.; Köhler, B.; Sanderson, T. The elastodynamic finite integration technique for waves in cylindrical geometries. J. Acoust. Soc. Am. 1998, 104, 2604-2614. [CrossRef]

32. Leckey, C.A.; Rogge, M.D.; Miller, C.A.; Hinders, M.K. Multiple-mode Lamb wave scattering simulations using 3D elastodynamic finite integration technique. Ultrasonics 2012, 52, 193-207. [CrossRef]

33. Luchinsky, D.G.; Hafiychuk, V.; Smelyanskiy, V.N.; Kessler, S.; Walker, J.; Miller, J.; Watson, M. Modeling wave propagation and scattering from impact damage for structural health monitoring of composite sandwich plates. Struct. Health Monit. 2013, 12, 296-308. [CrossRef]

34. Willberg, C.; Duczek, S.; Vivar-Perez, J.M.; Ahmad, Z.A.B. Simulation Methods for Guided Wave-Based Structural Health Monitoring: A Review. Appl. Mech. Rev. 2015, 67, 010803. [CrossRef]

35. Gravenkamp, H.; Prager, J.; Saputra, A.A.; Song, C. The simulation of Lamb waves in a cracked plate using the scaled boundary finite element method. J. Acoust. Soc. Am. 2012, 132, 1358-1367. [CrossRef] [PubMed]

36. Gravenkamp, H. Efficient simulation of elastic guided waves interacting with notches, adhesive joints, delaminations and inclined edges in plate structures. Ultrasonics 2018, 82, 101-113. [CrossRef] [PubMed]

37. Bunsell, A.R. Composite pressure vessels supply an answer to transport problems. Reinf. Plast. 2006, 50, 38-41. [CrossRef]

38. Scott, A.; Clinch, M.; Hepples, W.; Kalantzis, N.; Sinclair, I.; Spearing, S.M. Advanced micromechanical analysis of highly loaded hybrid composite structures. In Proceedings of the 17 th International Conference on Composite Materials, Edinburgh, UK, 27-31 July 2009.

39. Changliang, Z.; Mingfa, R.; Wei, Z.; Haoran, C. Delamination prediction of composite filament wound vessel with metal liner under low velocity impact. Compos. Struct. 2006, 75, 387-392. [CrossRef]

40. Matemilola, S.A.; Stronge, W.J. Low-Speed Impact Damage in Filament-Wound CFRP Composite Pressure Vessels. J. Press. Vessel. Technol. 1997, 119, 435-443. [CrossRef]

41. Wilcox, P.D. Lamb Wave Inspection of Large Structures Using Permanently Attached Transducers. Ph.D. Thesis , Imperial College London, London, UK, 1998.

42. Monkhouse, R.; Wilcox, P.; Cawley, P. Flexible interdigital PVDF transducers for the generation of Lamb waves in structures. Ultrasonics 1997, 35, 489-498. [CrossRef]

43. Ueberschlag, P. PVDF piezoelectric polymer. Sens. Rev. 2001, 21, 118-126. [CrossRef]

44. Seminara, L.; Pinna, L.; Valle, M.; Basiricò, L.; Loi, A.; Cosseddu, P.; Bonfiglio, A.; Ascia, A.; Biso, M.; Ansaldo, A.; et al. Piezoelectric Polymer Transducer Arrays for Flexible Tactile Sensors. IEEE Sens. J. 2013, 13, 4022-4029. [CrossRef]

45. Bulletti, A.; Capineri, L. Interdigital Piezopolymer Transducers for Time of Flight Measurements with Ultrasonic Lamb Waves on Carbon-Epoxy Composites under Pure Bending Stress. J. Sens. 2015. [CrossRef] 
46. Ren, B.; Lissenden, C.J. PVDF Multielement Lamb Wave Sensor for Structural Health Monitoring. IEEE Trans. Ultrason. Ferroelectr. Freq. Control 2016, 63, 178-185. [CrossRef] [PubMed]

47. Giannelli, P.; Bulletti, A.; Capineri, L. Charge-mode interfacing of piezoelectric interdigital Lamb wave transducers. Electron. Lett. 2016, 52, 894-896. [CrossRef]

(C) 2019 by the authors. Licensee MDPI, Basel, Switzerland. This article is an open access article distributed under the terms and conditions of the Creative Commons Attribution (CC BY) license (http:// creativecommons.org/licenses/by/4.0/). 